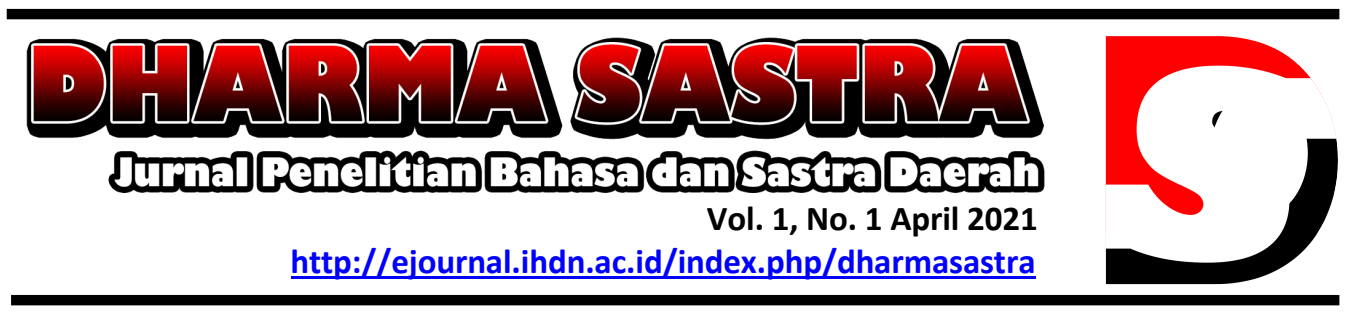

\title{
Optimalisasi Peran Pembelajaran Bahasa dan Sastra Indonesia sebagai Wahana Pembentukan Karakter Peserta Didik dalam Menghadapi Masyarakat Ekonomi Asean (MEA) ${ }^{1}$
}

\author{
Budhi Setiawan² \\ Universitas Sebelas Maret Surakarta ,Email : $\underline{\text { buset.74@gmail.com }}$
}

\begin{tabular}{l}
\hline \multicolumn{1}{c}{ Info Artikel } \\
\hline Diterima : 27 Maret 2021 \\
Direvisi : 31 Maret 2021 \\
Diterbitkan : 2 April 2021 \\
Keywords: \\
Indonesian Language \\
Education, the character \\
building, learners, \\
ASEAN Economic \\
Community \\
\end{tabular}

\begin{tabular}{l} 
Abstract \\
\hline The effectuation of ASEAN Economic Community as of 2015 has \\
demanded education institution to prepare qualified graduates \\
equipped with various competencies according to their own fields of \\
professionalism and expertise. In the ASEAN Economic Community \\
era, each nation is predicted to tightly compete as to be a \\
qualitatively and quantitatively prominent nation in its products \\
either in the economic sector, in the cultural sector, or in the \\
scientific and technological sector. It is necessary to be aware that \\
the excellence or superiority of a nation is measured not only on the \\
natural resources owned but also on the excellence of its human \\
resources, in this case, namely: graduates of education institutions \\
who are capable of encountering and dealing with all the future \\
challenges promptly amid the very tight competition. To produce \\
graduates with such profiles, at least a certain model of education \\
is required, namely: the education model which is effectively able \\
produce graduates bearing the expected characteristics. Similarly, \\
the Indonesian language education shall be able to prepare learners \\
with quality and excellence in the ASEAN Economic Community era. \\
The learners (graduates) who are well-prepared to encounter \\
ASEAN Economic Community shall bear the following: (1) in-depth \\
mastery of science and technology (content); (2) good \\
communication ability between the people; (3) high cognition or \\
reliable intelligence; and (4) the characterization of national culture.
\end{tabular}

\footnotetext{
${ }^{1}$ Makalah ini dipresentasikan pada Seminar Nasional dengan Tema "Pembelajaran Bahasa dan Sastra Agama sebagai Penguat Karakter Peserta Didik untuk Menghadapi Masyarakat Ekonomi di Asia" yang diselenggarakan oleh Jurusan Pendidikan Bahasa dan Sastra Agama, Fakultas Dharma Acarya, Institut Hindu Dharma Negeri (IHDN) di Bali 10 Juni 2016.
}

2 Dosen pada Program Studi Sarjana (S1), Magister (S2), dan Doktor (S3) Pendidikan Bahasa Indonesia, Fakultas Keguruan dan IImu Pendidikan, Universitas Sebelas Maret Surakarta. 
The four aspects can be materialized through character building on every subject matter including Indonesian Language education by maximizing the role of Indonesian Language education as a domain or vehicle for the character building. It is very important to be understood because a developed nation is not merely indicated by its sophisticated science and technology, and abundant natural resources, but how the characters of learners are precisely created through the learning process they follow.

\section{Pendahuluan}

Sebagaimana telah dipaparkan pada abstrak makalah ini, keunggulan suatu bangsa tidak hanya diparameteri oleh canggihnya IPTEK yang dikuasai, dan melimpahruahnya kekayaan alam yang dimiliki suatu bangsa, tetapi perlu juga dilihat bagaimana karakter-karakter yang ada pada diri manusia itu terbentuk. Akhir-akhir ini, di Indonesia, baik melalui media cetak, seperti surat kabar, majalah, maupun media elektronik, seperti siaran televisi, radio, dan sosmed melalui internet, diberitakan fenomena sosial yang cukup mencengangkan dan mencoreng dunia pendidikan kita, dengan terdedahkannya kasus seks bebas, video porno, dan tawuran pelajar. Simak kasus-kasus berikut.

Pada awal Oktober lalu, masyarakat dihebohkan dengan munculnya kasus video porno siswa SMP Negeri 4 Jakarta Pusat. Video berdurasi empat menit tersebut menampilkan adegan mesum sepasang pelajar yang dilakukan di dalam ruang kelas dan disaksikan temanteman pelaku.

Pada Rabu 6 November, Polresta Semarang melakukan razia di sebuah warnet yang terletak di Jalan Woltermongonsidi, Semarang. Razia dilakukan karena adaya laporan masyarakat yang diduga warnet tersebut dijadikan tempat mesum. Alhasil, masyarakat dibuat tercengang dengan ditangkapnya tiga pasang remaja berbugil ria sedang asyik menonton situs porno di tiga ruangan yang disekat-sekat.

Kasus-kasus seks bebas pelajar sebelumnya juga pernah terungkap pada 19 Oktober, Polres Kota Tobelo, Halmahera Utara (Halut) menangkap empat remaja yang sedang membuat video mesum di salah satu rumah kost di kawasan Desa MKCM Tobelo. Lebih memiriskan lagi para remaja yang membuat film layak sensor itu, ternyata masih tercatat sebagai siswa-siswi sebuah SMP ternama di Kota Tobelo.

Pada 23 September, sepasang pelajar kepergok mesum dengan teman wanitanya yang masih berpakaian seragam sekolah di sebuah bilik warung internet (warnet). Dua pelajar yang tertangkap basah sedang bermesraan tersebut, merupakan siswa salah satu SMA yang ada di Kabupaten Situbondo, Jawa Timur (Jatim).

Dua kelompok pelajar SMP terlibat tawuran di Jalan Pluit Raya Selatan, Penjaringan, Jakarta Utara. Seorang pelajar berhasil ditangkap warga yang resah dengan ulah para pelajar. Tiga pelajar yang berasal dari sekolah yang berbeda diamankan aparat Polsek Kebayoran Baru, Jakarta Selatan. Penangkapan 3 remaja itu menyusul aksi penyerangan terhadap bus Metromini S-75 jurusan Blok M-Pasar Minggu yang berisi beberapa pelajar.

Kondisi seperti yang digambarkan pada kasus-kasus di atas, menimbulkan kecurigaan masyarakat terhadap kegagalan pendidikan kita. Selama ini, pendidikan dan pembelajaran yang diselenggarakan di sekolah-sekolah, lebih mengutamakan porsi yang berlebih pada penanaman aspek-aspek pengetahuan dan kemampuan teknis (hard skills) semata, daripada porsi penanaman bagaimana kemampuan mengelola diri dan orang lain (soft skills). Padahal jika disadari, bahwa kesuksesan seseorang tidak ditentukan semata-mata oleh pengetahuan 
dan kemampuan teknis (hard skill) saja, tetapi lebih oleh kemampuan mengelola diri dan orang lain (soft skill). Hal ini mengisyaratkan bahwa mutu pendidikan karakter peserta didik sangat penting untuk ditingkatkan.

Salah satu upaya untuk mengurangi berbagai masalah di atas adalah dengan membenahi karakter anak bangsa. Jika masyarakat memiliki karakter yang kuat, maka berbagai tindakan amoral sebagaimana diungkap di atas dapat dihindari. Hal ini dapat dilakukan dengan memasukkan pendidikan karakter di dalam keluarga, masyarakat, dan di sekolah pada khususnya. Salah satu cara untuk membentuk siswa berkarakter di lingkungan sekolah yakni melalui pembelajaran bahasa dan sastra Indonesia.

Berdasarkan latar belakang di atas, permasalahan dalam tulisan ini ditekankan pada upaya-upaya apa sajakah yang dapat dilakukan melalui pembelajaran bahasa dan sastra Indonesia sebagai wahana pembentukan karakter peserta didik untuk menghadapi MEA. Mengacu pada permasalahan tersebut, tulisan ini bertujuan untuk memberikan masukan bagi pendidik (guru), sekolah, institusi-institusi lain, dan sumbangsih terhadap khalayak umum khususnya dunia pendidikan bahwasanya melalui pembelajaran bahasa dan sastra Indonesia bisa dijadikan wahana untuk menyampaikan pendidikan karakter kepada peserta didik.

\section{Metode}

Secara harfiah metode berarti pengejaran pengetahuan, penyelidikan, cara penuntutan penyelidikan, atau sistem semacam itu. Dalam beberapa abad terakhir ini lebih sering berarti proses yang ditentukan untuk menyelesaikan tugas. Beberapa juga menyebutkan bahwa metode adalah suatu proses atau cara sistematis yang digunakan untuk mencapai tujuan tertentu dengan efisiensi, biasanya dalam urutan langkah-langkah tetap yang teratur. Kata metode (method) berasal dari bahasa Latin dan juga Yunani, methodus yang berasal dari kata meta yang berarti sesudah atau di atas, dan kata hodos, yang berarti suatu jalan atau suatu cara. Metode dan sistem membentuk hakikat ilmu. Sistem bersangkutan dengan isi ilmu, sementara metode berkaitan dengan aspek formal. Lebih tepat, sistem berarti keseluruhan pengetahuan yang teratur atau totalitas isi dari ilmu.

Proses yang digunakan dalam penyelesaian penelitian ini adalah dengan menguraikan kata, bukan angka. Data yang digunakan dalam penelitian ini berupa teks yang analisisnya diuraikan secara deskriptif. Dengan demikian maka dalam penulisan ini menggunakan metode deskriptif kualitatif dan memanfaatkan pendekatan kepustakaan.

\section{Pembahasan}

Sebelum membahas lebih lanjut permasalahan tersebut, berikut ini secara berturut-turut perlu diuraikan beberapa konsep yang berkenaan dengan (1) pendidikan karakter, (2) peran pembelajaran bahasa dan sastra Indonesia, (3) penguatan karakter mahasiswa atau peserta didik dalam menghadapi MEA.

\section{Pendidikan Karakter}

Terdapat banyak definisi atau batasan tentang karakter yang dikemukakan oleh beberapa pakar. Karakter adalah bawaan, hati, jiwa, kepribadian, budi pekerti, perilaku, personalitas, sifat, tabiat, temperamen, watak. Adapun berkarakter adalah ber-kepribadian, berperilaku, bersifat, bertabiat, dan berwatak (Depdikbud, 2015). Hal ini sejalan dengan pendapat Majid \& Andayani (2011: 11), karakter diartikan sebagai tabiat, watak, sifat-sifat kejiwaan, akhlak dan budi pekerti yang membedakan seseorang dengan orang lain. Karakter merupakan nilainilai perilaku manusia yang berhubungan dengan Tuhan yang Mahaesa, diri sendiri, sesama 
manusia, lingkungan, dan kebangsaan yang terwujud dalam pikiran, sikap, perasaan, perkataan, dan perbuatan berdasarkan norma-norma agama, hukum, tata krama, budaya, dan adat istiadat (Tobroni, 2014). Menurut Simon Philips seperti dikutip Muslich (2011: 70), karakter adalah kumpulan tata nilai yang menuju pada suatu sistem yang melandasi pemikiran, sikap dan perilaku yang ditampilkan seseorang. Sementara itu, Hermawan Kertajaya (dalam Majid \& Andayani, 2011: 11) mendefinisikan karakter sebagai "ciri khas" yang dimiliki oleh suatu individu. Ciri khas tersebut adalah asli, dalam artian tabiat atau watak asli yang mengakar pada kepribadian individu tersebut, dan merupakan mesin pendorong bagaimana seseorang bertindak, bersikap, berujar, serta merespon sesuatu (Gunawan, 2012: 2).

Jika beberapa batasan di atas dikaitkan dengan pendidikan, maka dapat disintesiskan bahwa pada hakikatnya pendidikan karakter adalah proses pemberian tuntunan kepada peserta didik untuk menjadi manusia seutuhnya yang berkarakter dalam dimensi pikir, hati, raga, serta rasa dan karsa. Pendidikan karakter dapat dimaknai sebagai pendidikan nilai, pendidikan moral, pendidikan budi pekerti, pendidikan watak yang bertujuan mengembangkan kemampuan peserta didik untuk dapat memberikan keputusan baik-buruk, memelihara apa yang baik, dan mewujudkan kebaikan itu dalam kehidupan sehari-hari dengan sepenuh hati, sehingga akan terbentuklah peserta didik yang diberi tuntunan tersebut sebagai individu yang beriman dan bertakwa kepada Tuhan yang Mahaesa, berakhlak mulia, berilmu, cakap, sehat, mandiri, kreatif, demokratis, dan bertanggung jawab. Menurut Megawangi (2003), kualitas karakter manusia meliputi sembilan pilar, yaitu (1) Cinta Tuhan dan segenap ciptaan-Nya; (2) Tanggung jawab, Disiplin dan Mandiri; (3) Jujur/amanah dan Arif; (4) Hormat dan Santun; (5) Dermawan, Suka menolong, dan Gotong-royong; (6) Percaya diri, Kreatif dan Pekerja keras; (7) Kepemimpinan dan adil; (8) Baik dan rendah hati; (9) Toleran, cinta damai dan kesatuan. Orang yang memiliki karakter baik adalah orang yang memiliki kesembilan pilar karakter tersebut.

Sebagai pelaku dalam proses pendidikan di sekolah, guru berperan penting dalam menumbuhkan karakter peserta didik. Oleh karenanya, dia dituntut terus untuk melakukan perbaikan, dan meningkatkan kualitas dirinya dalam mendidik dan membangun karakter peserta didiknya. Beberapa upaya yang bisa mereka lakukan adalah dengan meningkatkan keteladanan dan pembiasaan disiplin pendidik, serta penciptaan suasana belajar yang kondusif.

\section{Peran Pembelajaran Bahasa dan Sastra Indonesia}

Di dunia pendidikan, khususnya di sekolah-sekolah, pendidikan karakter dapat dijalankan manakala kurikulum yang berwawasan karakter tersedia di dalamnya. Jika dicermati, Kurikulum 2013 (Kurtilas) yang berlaku di pendidikan dasar dan menengah, serta Kurikulum Pendidikan Tinggi (KPT) berbasis Standar Kompetensi Lulusan (lihat Permenristekdikti No. 44 Tahun 2015) yang berlaku untuk perguruan tinggi, secara tersurat pendidikan karakter telah dirumuskan melalui standar kompetensi atau capaian pembelajaran yang berada pada aspek sikap. Setiap mata pelajaran ataupun mata kuliah, standar kompetensi atau capaian pembelajaran harus dirumuskan ke dalam tiga ranah, yaitu ranah sikap, ranah pengetahuan, dan ranah keterampilan. Demikian juga dengan mata pelajaran bahasa dan sastra Indonesia.

Tujuan pembelajaran bahasa dan sastra Indonesia, pada hakikatnya adalah agar peserta didik: (1) memiliki sikap positif terhadap bahasa Indonesia sebagai bahasa Nasional maupun bahasa Negara; (2) memiliki pengetahuan dan pemahaman yang memadai tentang bahasa Indonesia, baik sebaik bahasa Nasional maupun bahasa Negara; (3) memiliki keterampilan 
menggunakan bahasa Indonesia dalam berkomunikasi secara lisan maupun tulisan dengan baik dan benar; dan (4) memiliki kemampuan mengapresiasi yang baik terhadap hasil karya sastra Indonesia.

Dalam kaitannya dengan pendidikan karakter, Waluyo (1989: 21) mengutip pendapatnya Moody dalam bukunya The Teaching of Literature mengemukakan bahwa ada lima hal yang dapat diperoleh dari belajar sastra, yaitu (1) untuk memupuk keterampilan berbahasa; (2) untuk melatih kepekaan dan keiindahan; (3) untuk mampu menghayati tema-tema kemanusiaan, moral, budi pekerti yang luhur (atau dengan kata lain kemampuan membedakan baik buruk); (4) untuk memahami watak sesama manusia, perbedaan antara yang satu dengan yang lain sehingga melatih solidaritas; dan (5) untuk melatih kepekaan sosial dalam arti memahami penderitaan orang lain. Muatan nilai-nilai edukatif yang tersirat dari karya sastra pada umumnya adalah nilai-nilai religius, nilai moral, nilai sosial, dan nilai etika, serta nilai estetika. Dalam konteks pembelajaran bahasa dan sastra Indonesia, guru dapat menanamkan nilai-nilai edukatif tersebut melalui apresiasi karya sastra. Dalam proses pembelajaran bahasa dan sastra Indonesia, guru harus menyampaikan hal-hal tersebut agar peserta didik dapat membedakan mana yang baik dan mana yang buruk, yang pada akhirnya bisa melakukan hal yang baik, dan meninggalkan hal yang buruk. Namun, sebelum guru/pendidik memerintahkan kepada peserta didik untuk melakukan suatu hal yang baik, dia sendiri harus berkarakter baik. Untuk itu, guru/pendidik harus selalu meningkatkan kualitasnya dalam membangun karakter. Upaya ini dapat dilakukan dengan peningkatan keteladanan dan pembiasaan disiplin pendidik, serta penciptaan suasana belajar yang kondusif (Hidayatullah, 2010)

Keteladanan dalam pendidikan merupakan pendekatan atau metode yang sangat berpengaruh dan terbukti paling berhasil dalam mempersiapkan, membentuik, dan mengembangkan karakter peserta didik. Sebagai contoh jika guru memiliki kebiasaan membaca, biasanya akan memberikan inspirasi kepada peserta didiknya untuk ikut membaca. Demikian juga untuk hal-hal baik lain yang diteladankan guru kepada peserta didik akan ikut memberikan inspirasi untuk melakukan sesuatu. Jadi, dapat disimpulkan bahwa keteladanan member kontribusi besar dalam mendidik karakter.

Kedisiplinan pada hakikatnya adalah kebiasaan dan kesadaran untuk melakukan sesuatu hal sesuai aturan yang berlaku dalam lingkungan tertentu. Bilamana guru/pendidik selalu disiplin, maka peserta didik akan segan kepadanya, yang pada akhirnya mereka akan terbiasa untuk berdisiplin.

Suasana belajar yang kondusif. Semua guru harus memiliki sikap peduli dalam membentukk karakter peserta didik. Oleh karena itu, guru harus memiliki sikap proaktif dalam mendidik karakter peserta didiknya. Selain faktor keluarga dan sekolah, lingkungan masyarakat juga berperan penting dalam pembentukan karakter. Lingkungan masyarakat yang beriklim belajar kondusif, akan membuat peserta didik termotivasi untuk mengikuti kebiasaan yang berlaku dalam masyarakat, begitu juga sebaliknya.

\section{Penguatan Karakter Mahasiswa atau Peserta Didik dalam Menghadapi MEA}

Era MEA yang telah dicanangkan pada Desember 2015 yang silam, mau tidak mau, siap ataupun tidak siap, masyarakat Indonesia dituntut untuk memiliki mental dan karakter yang kuat dan luar biasa. Mengapa demikian? Karena di era MEA tersebut, masyarakat Indonesia, akan bertarung, bersaing, atau berkompetisi dengan negara-negara di luar Indonesia, khususnya negara-negara ASEAN. Salah satu upaya yang dapat ditempuh dalam menyiapkan 
masyarakat Indonesia yang bermental dan berkarakter kuat dan luar biasa bisa melalui jalur pendidikan.

Pendidikan merupakan usaha sadar dalam mewariskan nilai-nilai luhur bangsa kepada generasi penerus, sehingga diharapkan tercipta anak-anak bangsa yang unggul berintelektual tinggi, berkepribadian kuat, dan beridentitas nasional dengan tetap memegang teguh pada budaya sendiri sebagai lambang jati diri bangsa. Pendidikan dan pembentukan karakter sesuai dengan yang tercantum dalam fungsi dan tujuan pendidikan nasional. Oleh karena itu, dunia pendidikan harus merespon dengan tepat agar dapat menyiapkan SDM yang berkualitas. Dengan penguatan karakter pada peserta didik atau mahasiswa diharapkan mampu menciptakan generasi-generasi penerus bangsa yang siap bersaing pada era MEA.

Karakter merupakan aktualisasi dari soft skill seseorang. la merupakan cara berpikir, bersikap, dan berperilaku yang merupakan ciri khas dari seseorang dan bekerjasama dengan orang lain dan mampu bertanggungjawab dengan apa yang menjadi keputusannya. Soft skill pada peserta didik (mahasiswa) dapat dibangun dan dikembangkan. Oleh karena itu, pengembangan soft skill melalui berbagai pelatihan tidak jauh berbeda dengan apa yang sekarang dikenal dengan pengembangan karakter bangsa. Jadi, konsep soft skill maksudnya tidak lain adalah karakter (Marzuki, 2012).

Mahasiswa yang memiliki soft skill akan lebih siap dalam menghadapi persaingan dalam era MEA. Menurut Illah Sailah (2007), bahwa pendidikan di Indonesia muatan soft skills hanya $10 \%$ sedangkan hard skills $90 \%$, begitu juga Menurut penelitian di Harvard University Amerika Serikat ternyata kesuksesan seseorang tidak ditentukan semata-mata oleh pengetahuan dan kemampuan teknis (hard skills) saja, tetapi lebih oleh kemampuan mengelola diri dan orang lain (soft skills), Penelitian ini mengungkapkan, kesuksesan hanya ditentukan sekitar $20 \%$ oleh hard skills dan sisanya $80 \%$ oleh soft skills. Elfindri, dkk. (2011:68) menyatakan hasil penelitian psikologi sosial menunjukkan bahwa orang yang sukses di dunia ditentukan oleh peranan ilmu sebesar $18 \%$, sisanya $82 \%$ dijelaskan oleh keterampilan emosional soft skills dan jenisnya.

Suatu program studi dinyatakan baik oleh perguruan tinggi, jika lulusannya memiliki waktu tunggu yang singkat untuk mendapatkan pekerjaan pertama, namun dunia kerja mengatakan bukan itu, melainkan seberapa tangguh seorang lulusan untuk memiliki komitmen atas perjanjian yang telah dibuatnya pada pekerjaan pertama. Oleh karena itu, setiap kelulusan Perguruan Tinggi harus dibekali dengan pembangunan karakter yang terintegrasi pada proses kegiatan perkuliahan. Sesuai dengan Fungsi Pendidikan Nasional yang tertuang dalam UU No 20 Tahun 2003 tentang Sisdiknas menyatakan bahwa Pendidikan nasional berfungsi mengembangkan kemampuan dan membentuk watak serta peradaban bangsa yang bermartabat dalam rangka mencerdaskan kehidupan bangsa, bertujuan untuk berkembangnya potensi peserta didik agar menjadi manusia yang beriman dan bertakwa kepada Tuhan Yang Maha Esa, berakhlak mulia, sehat, berilmu, cakap, kreatif, mandiri, dan menjadi warga negara yang demokratis serta bertanggung jawab. Hal tersebut menegaskan bahwa tujuan pendidikan bukan hanya sekedar pengajaran ilmu, tetapi juga bertujuan membina dan mengembangkan potensi subjek didik menjadi manusia yang berbudaya, sehingga diharapkan mampu memenuhi tugasnya sebagai manusia yang diciptakan Allah Tuhan Semesta Alam dan sekaligus menjadi warga negara yang berarti dan bermanfaat bagi suatu Negara.

Thomas Lictona dalam Rukiyati (2014) mengatakan bahwa pendidikan karakter adalah upaya mengembangkan kebajikan sebagai fondasi dari kehidupan yang berguna, bermakna, produktif dan fondasi untuk masyarakat yang adil, penuh belas kasih dan maju. Karakter yang 
baik meliputi tiga komponen utama, yaitu: moral knowing, moral feeling, moral action. Moral knowing meliputi: sadar moral, mengenal nilai-nilai moral, perspektif, penalaran moral, pembuatan keputusan dan pengetahuan tentang diri. Moral feeling meliputi: kesadaran hati nurani, harga diri, empati, mencintai kebaikan, kontrol diri dan rendah hati. Moral action meliputi kompetensi, kehendak baik dan kebiasaan Pendidikan karakter penting diajarkan untuk menjadi manusia yang cerdas, jujur, tangguh, dan peduli. Keempat hal tersebut beralasan untuk menjadi kunci sukses. Apabila mempunyai kecerdasan maka akan bisa memilah mana yang baik dan salah. Kecerdasan, harus diimbangi dengan kejujuran untuk mendapatkan kepercayaan orang lain, sedangkan tangguh diperlukan karena yang bermain dalam MEA 2015 bukan hanya masyarakat Indonesia tapi juga negara lain di ASEAN. Sikap peduli tidak kalah pentingnya dengan ketiga hal tadi, karena dengan sikap peduli dengan orang lain, maka akan mudah untuk menjaga hubungan baik dengan yang lain.

\section{Kesimpulan}

Pembelajaran bahasa dan sastra Indonesia, dapat dijadikan salah satu wahana dalam pembentukan dan penyampaian pendidikan karakter kepada peserta didik, dan penanaman nilai-nilai yang baik. Sebagai salah satu wahana atau metode dalam pembentukan dan pendidikan karakter, pembelajaran bahasa dan sastra Indonesia yang berwawasan karakter akan menghantarkan proses pendidikan menuju yang lebih baik di tengah kondisi bangsa yang mengalami kebangkrutan moral, maraknya tindak kekerasan, pelecehan seksual, dan kriminal yang tengah menjalar dan menjangkiti bangsa ini. Pembelajaran bahasa dan sastra Indonesia mampu dijadikan sebagai media atau strategi dalam menanamkan nilai-nilai moral kebajikan kepada peserta didik, seperti kejujuran, pengorbanan, demokrasi, santun dan sebagainya.

Berbagai upaya yang dapat dilakukan pendidik melalui pembelajaran bahasa dan sastra Indonesia untuk menanamkan karakter peserta didik dapat dilakukan melalui bahan kajian keterampilan berbahasa, santun berbahasa, apresiasi puisi, lagu, cerpen, novel, drama, dan cerita rakyat. Melalui upaya yang serius, dan ditangan guru-guru atau pendidik yang berkarakter kuat dan cerdas, Insya Allah karakter bangsa ini bisa dibenahi.

\section{Daftar Pustaka}

Depdikbud. (1995). Kamus Besar Bahasa Indonesia. Jakarta: Balai Pustaka.

Elfindri, dkk. (2011). Soft Skills untuk Pendidik. Yogyakarta: Praninta Offset

Gunawan, Heri. (2012). Pendidikan Karakter Konsep dan Impementasi. Bandung: Alfabeta.

Hidayatullah, Furqon. (2010). Pendidikan Karakter: Membangun Peradaban Bangsa. Surakarta: Yuma Pustaka.

Majid, Abdul \& Andayani, Dian. (2011) Pendidikan Karakter Perspektif Islam. Bandung: Remaja Rosdakarya.

Marzuki . (2012). "Pengembangan Soft Skill Berbasis Karakter Melalui Pembelajaran IPS Sekolah Dasar". Makalah Seminar Nasional di IKIP PGRI Madiun.

Megawangi, Ratna. (2003). Pendidikan Karakter untuk Membangun Masyarakat

Madani. IPPK Indonesia Heritage Foundation.

Muslich, Masnur. (2011). Pendidikan Karakter Menjawab Tantangan Krisis Multidimensional. Jakarta: Bumi Aksara.

Rukiyati, Y. Ch dkk. (2014). "Penanaman Nilai Karakter Tanggung Jawab dan Kerja Sama Terintegrasi dalam Perkuliahan IImu Pendidikan" Jurnal Pendidikan Karakter, Tahun IV, Nomor 2, Juni 2014. 
Sailah, Illah. (2007). Pengembangan Soft Skills di Perguruan Tinggi, Sosialisasi Pengembangan Soft Skills di Kopertis VII Surabaya

Tobroni. (2014). Pendidikan Karakter dalam Perspektif Islam. (http://tobroni.staff.umm.ac.id/2010/11/24/pendidikan-karakter-dalam-perspektifislampendahulan/. Diunduh pada 19 Oktober 2014.

Waluyo, Herman Josep. (1989). Apresiasi dan Pengajaran Sastra. Surakarta: Sebelas Maret University Press. 